\title{
Using an Artificial Neural Network to Validate and Predict the Physical Properties of Self-Compacting Concrete
}

\author{
K. Thirumalai Raja, ${ }^{1}$ N. Jayanthi, ${ }^{2}$ Jule Leta Tesfaye, ${ }^{3,4}$ N. Nagaprasad $\left(\mathbb{D},{ }^{5}\right.$ \\ R. Krishnaraj $\mathbb{D}^{4,6}$ and V. S. Kaushik ${ }^{7}$ \\ ${ }^{1}$ Department of Civil Engineering, SNS College of Technology, Coimbatore, Tamil Nadu, India \\ ${ }^{2}$ Department of Computer Science and Engineering, KPR Institute of Engineering and Technology, Coimbatore, \\ Tamil Nadu, India \\ ${ }^{3}$ Department of Physics, College of Natural and Computational Science, Dambi Dollo University, Dembi Dolo, Ethiopia \\ ${ }^{4}$ Centre for Excellence-Indigenous Knowledge, Innovative Technology Transfer and Entrepreneurship, Dambi Dollo University, \\ Dembi Dolo, Ethiopia \\ ${ }^{5}$ Department of Mechanical Engineering, ULTRA College of Engineering and Technology, Madurai-625104, Tamilnadu, India \\ ${ }^{6}$ Department of Mechanical Engineering, College of Engineering and Technology, Dambi Dollo University, Dembi Dolo, Ethiopia \\ ${ }^{7}$ Department of Mechanical Engineering, SNS College of Technology, Coimbatore, Tamil Nadu, India
}

Correspondence should be addressed to R. Krishnaraj; prof.dr.krishnaraj@dadu.edu.et

Received 22 October 2021; Revised 8 December 2021; Accepted 10 December 2021; Published 6 January 2022

Academic Editor: Fuat Kara

Copyright (c) $2022 \mathrm{~K}$. Thirumalai Raja et al. This is an open access article distributed under the Creative Commons Attribution License, which permits unrestricted use, distribution, and reproduction in any medium, provided the original work is properly cited.

\begin{abstract}
SCC (self-compacting concrete) is a high-flowing concrete that blasts into structures. Many academics have been interested in using an artificial neural network (ANN) to forecast concrete strength in recent years. As a result, the goal of this study is to confirm the various possibilities of using an artificial neural network (ANN) to detect the features of SCC when Portland Pozzolana Cement (PPC) is partially substituted with biowaste such as Bagasse Ash (BA) and Rice Husk Ash (RHA) (RHA). Specialist systems based on the fully connected cascade (FCC) architecture in artificial neural networks (ANN) are used to estimate the compressive toughness of SCC. The research results are confirmed with the forecasting results of ANN utilizing 73 trial datasets of differentiation focus proposals of cement, BA, and RHA containing parameters such as initial setting time (IST), final setting time (FST), and standard consistency. Experiments to determine compressive strength for a wider range of mixed prepositions will result in higher project expenses and delays. So, an expert system ANN is used to find the standard consistency, setting time, and compressive strength for the intermediate mix propositions according to IS 10262:2009. The experimental results of compressive strength for 28 days are considered, in which $70 \%$ was used to train the ANN and $30 \%$ was utilized for testing the accuracy of the predicted compressive strength for the intermediate mix proposition. Using all of the datasets, the number of hidden layers used for compressive strength prediction for intermediate mix proposal is determined in the first step. The compressive strength for the intermediate mix preposition was identified in the second phase of the research, using the number of hidden layers determined in the first phase. The results were validated using the correlation coefficient $(R)$ and root mean square error (RMSE) obtained from ANN, resulting in an acceptance range of 97 percent to 99 percent.
\end{abstract}

\section{Introduction}

SCC has high compactness without requiring external vibration, which through imperfections bleeding, permeability, and segregation is eradicated [1]. To reduce the cost of construction of highly congested reinforced areas, SCC is used. The vital task in SCC is determining the mix proposition of ingredients. To address this challenge, many researchers proposed various methods like controlling the maximum coarse aggregate particle size to the total volume, reducing the volume ratio of aggregate to cementitious material, using various viscosity-enhancing admixtures 
(VEA) [2], increasing the paste volume and water-cement ratio (w/c), and so forth. To get an SCC mix of anticipated characteristics, the large number of experimental trials is vital, which leads to an increase in materials cost and wastage of time [3]. Manipulation of several mixture variables is mandatory to get the SCC with the adequate flow and mechanical properties. Due to the practical issues of Aggarwal P and Aggarwal Y research community to properly focus on the theoretical links between the dosage of the mixture and the measurable technical qualities of SCC, preparation of SCC has increasingly become more difficult.

\subsection{Introduction to ANN and Related Work. ANN is a} dominant approach that gives feasible solutions to problems that are challenging to solve by using conventional techniques such as multiple regression models and other statistical models [4]. Nowadays, in the present context, ANN is used to improve the research process applications, resulting in optimal use of valuable resources like time and money. Using input and output variables, modeling is performed without any restrictions on the quantity of input which is stated by the authors [5]. ANN has been used in various civil engineering research processes such as damage detection in structures performance, concrete analysis, materials behavior modeling, monitoring the groundwater, and optimization of structures. Since ANN is a nonlinear model, researchers are applying this approach to predict the viable mix propositions to be taken as inputs to ANN for analyzing the mechanical properties of hardened concrete. Some of the research works addressed by researchers in this direction are elaborated on below.

Using the multiple-inputs and multiple-output model of ANN, compression, tensile strength, and flexural strength have been predicted by Mansoor et al. [6]. In this work, new variables related to curing conditions, change of type, and percentage of additives have been used to predict the compressive strength of SCC. Al Khatib M and Al Martini S employed ANN in the concrete industry to predict the quality of fresh self-consolidating concrete mixes in hot weather to eliminate lengthy trial process application and error testing programs. According to Uysal $M$ and Tanyildizi $\mathrm{H}$, the ANN model is utilized as an alternate strategy for estimating the core compressive capacity of SCC composites with mineral additives, which is used to evaluate the core compressive toughness of SCC combinations with mineral additives. Prasad BR used artificial neural networks to forecast a broad variation of compressive strengths of concrete ranging from around 30 to $60 \mathrm{MPa}$ [7]. The concrete design predicted using ANN addressed by [8] is expected to have optimum water and cement contents that result in high durability and better ecological and economic effects. It has been mentioned [9] that the ANN model could be employed to estimate the compressive strength of concrete that can be used in underwater construction which includes a combination of chemical admixtures. Dias and Pooliyadda [10] proved that an ANN model is superior to multiple regression ones, reducing the scatter of predictions.
Researchers have exhaustively explored the usage of ANN in the prediction of the behavior of SCC during its fresh and hardened states. Due to the nonavailability of proper mix design procedure and guidance in designing the mix proportions for SCC, researchers are cornered to carry out repeated number of the trial processes to arrive at an approximate mixed proportion of SCC with the available resources. Krishnasamy and Palanisamy [11] reported that either BA or RHA or a combination of BA and RHA showed progressive results in the replacement of Portland Pozzolana Cement (PPC) for the preparation of SCC. It was further concluded that $8 \%$ replacement of $\mathrm{BA}$ or $\mathrm{RHA}$ or $\mathrm{BA}+\mathrm{RHA}$ over the PPC in the practice of SCC shows significant results during its fresh and hardened state. Dataset from the paper has been used to predict the compressive strength for different replacement content to PPC. With that aim, the objective of the present work is to predict the SC, IST, and FST for the different replacement \% of BA or RHA or $\mathrm{BA}+\mathrm{RHA}$ to the PPC for which experimental investigation was not carried out and also to predict the CS for the intermediate mix proportions of BA or RHA or BA + RHA to PPC with predicted SC, IST, and FST as input for which experimental investigation was carried out.

As shown in Figures 1 and 2, the ANN network model that was utilized to forecast the compressive strength throughout this study effort may be found here. According to the authors, the FCC design of the ANN model is employed in this research, since it has been demonstrated to be hundreds of times more potent than the usual single hidden layer (SHL) architecture [12]. The results of [13] demonstrated that artificial neural networks (ANNs) have significant potential as a practical method for estimating compressive strength and slump values. According to [14], an alternate approach for forecasting the compressive strength of ground powdered blast furnace slag concrete utilizing concrete materials as input variables can be found in artificial neural networks (ANNs). According to [10], neural networks can be employed for a specific problem when variance in the supplied data is forecasted and is acceptable and when a defined technique is not accessible. The authors went on to say that neural network models can make predictions that were entirely accurate in most cases. As per [15], it was found that even though numerous elements determine concrete strength, multilayer feedforward neural network (MFNN) models have high precision in predicting concrete strength and demonstrated that artificial neural networks (ANNs) might be used to forecast maximum compressive strength of concrete with greater efficiency and accuracy compared to a model based on regression analysis and traditional approaches. Additionally, when compared to conventional methods, artificial neural networks (ANNs) can save a large quantity of computational effort and assist in the solution of more complex issues. Some articles have employed artificial neural networks to predict SCC and superior efficiency concrete qualities [16-18]. As a result, artificial neural networks (ANNs) are being used in a variety of civil engineering applications, including detecting structural damage [19], optimizing the structure [15], modeling the behavior of materials [20], and 


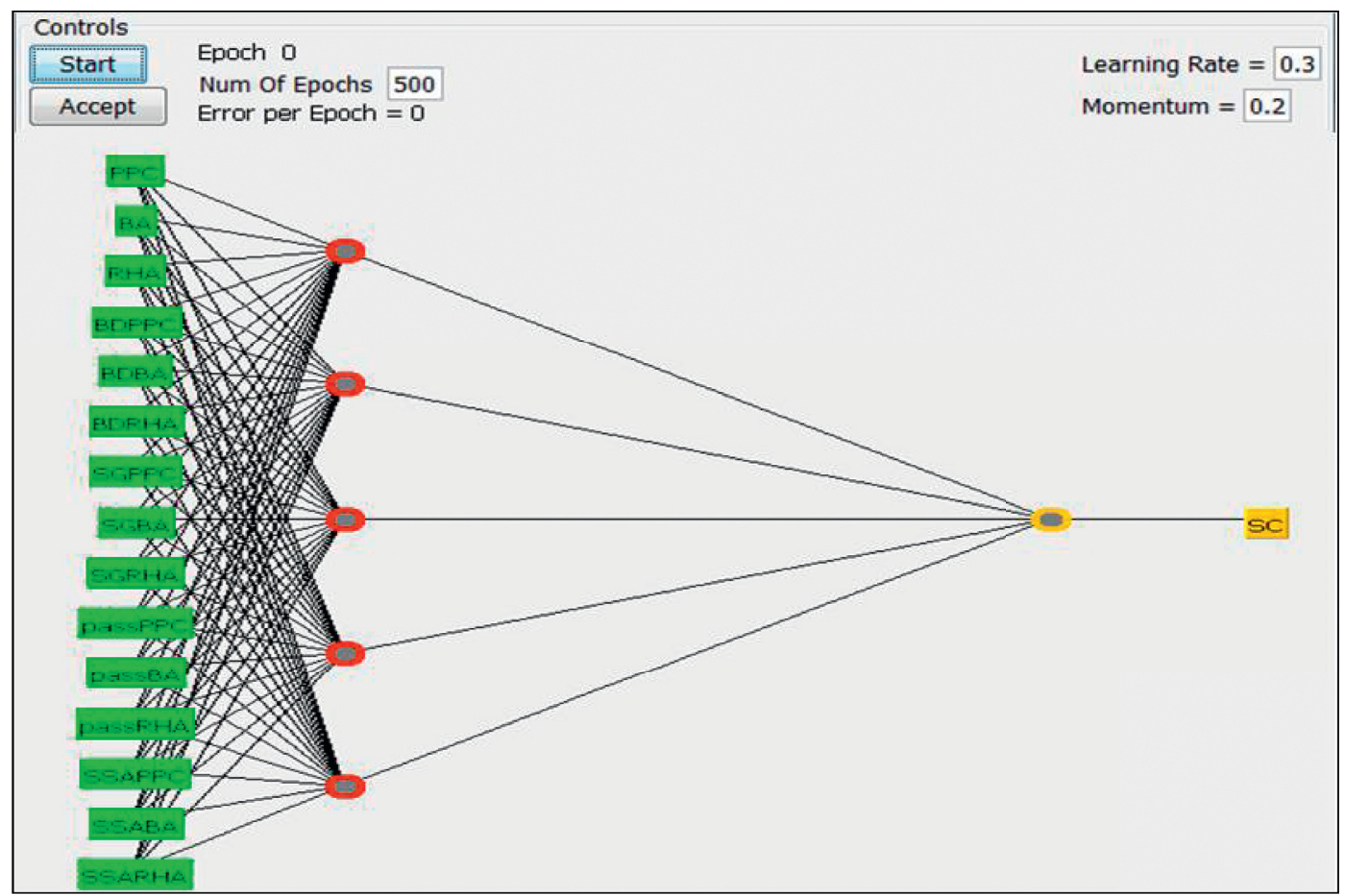

FIgURe 1: ANN model (PPC: Portland Pozzolana cement; BA: bagasse ash; RHA: rice husk ash; BDPPC, BDBA, and BDRHA: bulk density of PPC, BA, and RHA; SGPPC, SGBA, and SGRHA: specific gravity of PPC, BA, and RHA; passPPC, passBA, and passRHA: percentage passing $45 \mu \mathrm{m}$ in the sieve; SSAPPC, SSABA, and SSARHA: specific surface area of PPC, BA, and RHA).
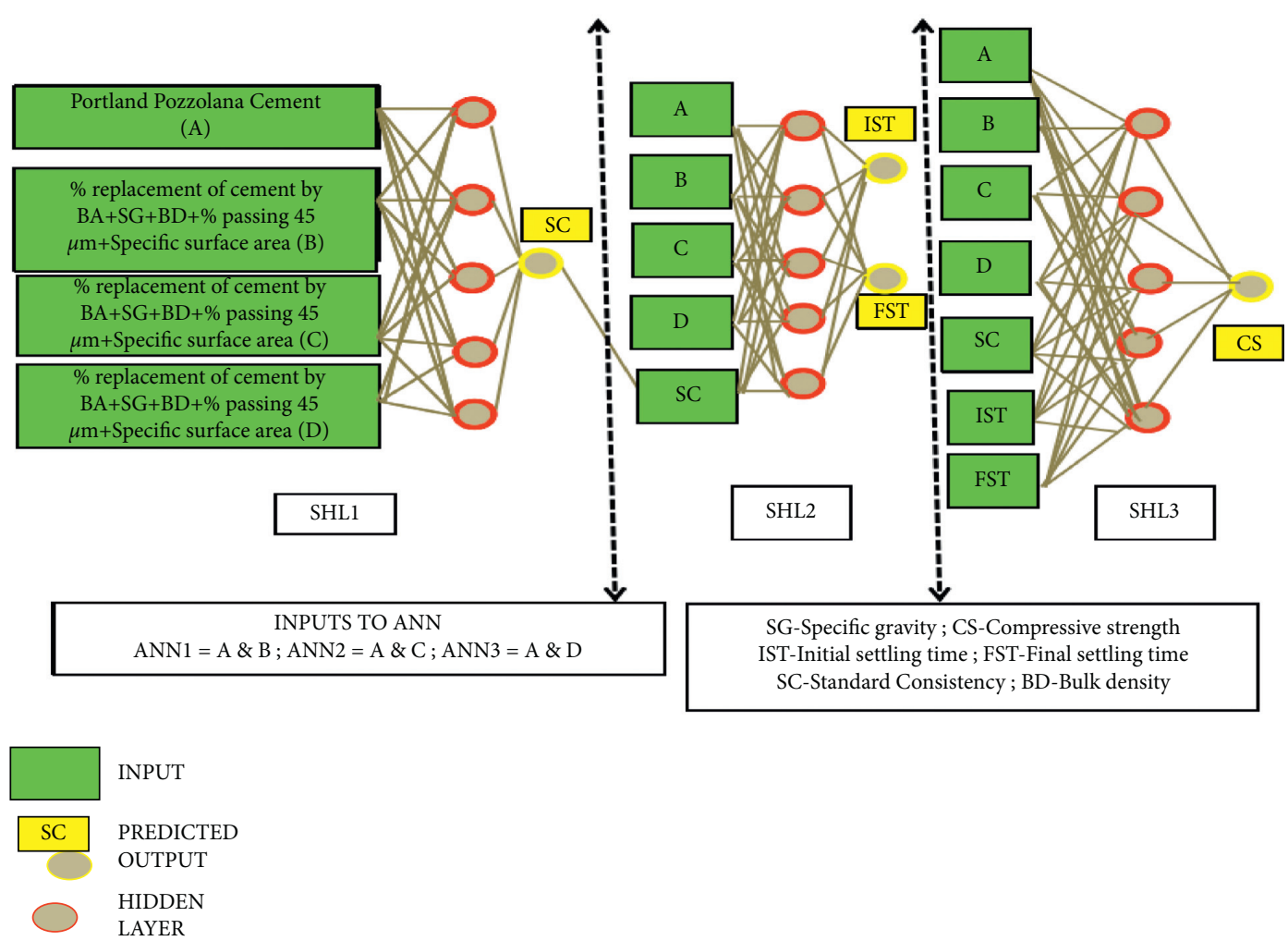

Figure 2: Proposed FCC ANN model $(\mathrm{A} \longrightarrow \mathrm{PPC} ; \mathrm{B} \longrightarrow \mathrm{BA}+\mathrm{SG}+\mathrm{BD}+$ percentage passing $45 \mu \mathrm{m}+$ specific surface area; $\mathrm{C} \longrightarrow \mathrm{RHA}+\mathrm{SG}+\mathrm{BD}+$ percentage passing $45 \mu \mathrm{m}+$ specific surface area; $\mathrm{D} \longrightarrow \mathrm{BA}+\mathrm{RHA}+\mathrm{SG}+\mathrm{BD}+$ percentage passing $45 \mu \mathrm{m}+$ specific surface area. For ANN1, inputs are both A and B; for ANN2, A and C; for ANN3, A and D). 
developing a model for the mixtures of flowable concrete in submerged constructions [21]. ANNs are also used for the optimization of the hidden units to get the highest accuracy $[19,22-25]$. The study in [26] dealt with ANN modeling of a cutting process to forecast the damage factor using experimental values and found that using ANN to estimate the damage factor in end milling of glass fibre reinforced plastic (GFRP) composite materials is highly recommended instead of expensive and time-consuming trials. The use of ANNs rather than complex and time-consuming experimental research to estimate engine performance and exhaust gas temperature is strongly suggested in the paper in [27]. According to [28], the use of ANN for predicting cutting temperatures without completing difficult, expensive, and time-consuming experimental experiments is highly recommended. According to the article in [29], the ANN's learning ability is quite powerful in estimating the geometric shape of things; hence, its employment is highly suggested.

The majority of research has attempted to estimate the compressive strengths of cement by utilizing all component propositions in each of the hidden layers and by using a random number of hidden layers. A random number of hidden layers are used for their simulation work, resulting in inaccurate prediction values.

So, in this work, the best single hidden layer (SHL) architecture was identified by a varying number of hidden layers, and it was used to forecast the final compressive strength. Also, three SHLs were connected serially, and SHL1 predicts standard consistency which is fed as one of the inputs to SHL2 and SHL3. SHL2 predicts the IST and FST of cement, which are fed into SHL3. SHL3 predicts the compressive strength using the predicted SC from SHL1 and the compressive strength using the predicted SC from SHL1 and predicted IST and FST from SHL2 as shown in Figure 2.

1.2. Source of the Experimental Dataset. As a binding medium, Krishnasamy and Palanisamy [11] employed Portland Pozzolana cement focused on Indian standard code IS: 1489-1991, which includes 22.5 percent fly ash, according to their research (FA). RHA was gathered using modernized rice mills in Kangayam, which is located in the state of Tamil $\mathrm{Nadu}$, South India. The acquired ashes were fed in the furnace for around 3 hours at a fixed temperature of $800^{\circ} \mathrm{C}$ to achieve the amorphous condition, which took approximately 3 hours. After cooling with air, the specimens were sieved through a 45-micron sieve. Using BA, we collected firewood from the local sugar plants, where bagasse is utilized as fuel. In order to achieve a uniform temperature of $800^{\circ} \mathrm{C}$, the BA specimens were held in the furnace for 8 hours. The specimens were then allowed to cool before being sieved through a 45-micron sieve and included in the concrete mix. The specimens were then allowed to cool before being sieved through a 45-micron sieve and included in the concrete mix for the plain M25 grade concrete [11]. For the preparation of plain cement concrete, $1: 1.54: 2.20$ mix ratios were used with 0.33 as SC. One percentage of Super Plasticizer (SP) with 0.30 percentage of Viscosity
Modifying Agent (VMA) has been determined after a variety of trial blends were conducted to ensure that excellent workability was attained without segregation or bleeding $[14,30,31]$.

\section{Results and Discussion}

The data samples for training and testing the ANN network were collected from the experimental results carried out by the authors in [11] by varying the percentage replacement of cement by BA or RHA or both BA + RHA in the order of $4 \%$, $8 \%, 12 \%, 16 \%$, and $20 \%$ in the concrete mixture. Summing to a total of 73 sets of experimental data, Tables 1-3 were validated by using the predicted values from the FCC type of ANN network by using WEKA tool, version 3.6.9. The PPC, BA, RHA, bulk density (BD), specific gravity (SG), percentage passing $45 \mu \mathrm{m}$, and specific surface area $\left[\mathrm{m}^{2} / \mathrm{kg}\right]$ are given as input to the ANN. Some of the input parameters values used in ANN are as given in Table 4. The number of neurons used in the simulation is $2 / 3$ of the input layer size plus the output layer. At each phase, $70 \%$ of the dataset is utilized for training the network, while $30 \%$ is used to test the proposed network.

The predicted compressive strength of concrete is recorded as the output of ANN network. The simulation results were recorded by varying hidden layers from 2 to 10 to identify the best architecture using the correlation coefficient $(R)$ and root mean square error (RMSE) as stopping criteria for the epochs value of 500, the learning rate of 0.3 , and momentum of 0.2 . The $R$ and RMSE values are calculated using equations (1) and (2). The 73 experimental datasets are used to train the ANN network to identify the best architecture [32-37].

$$
R=\frac{\sum_{i}^{n} Y X}{\sqrt{n\left(\sum_{I} Y\right)^{2}-\left(\sum_{I} Y^{2}\right)} \sqrt{n\left(\sum_{i} X\right)^{2}-\left(\sum_{i} X\right)^{2}}}
$$

$\mathrm{RMSE}=\sqrt{\frac{1}{n}} \sum_{i=1}^{n}(Y-X)^{2}$,

where " $X$ " is the predicted value, " $Y$ " is the experimental value, and " $n$ " is the total number of datasets. From Table 5, the maximum $R$ value was obtained as 0.9823 and the minimum RMSE value was 0.9214 for 5 hidden layers. To validate and predict the compressive strength for 28 days, the 5 hidden layers are used in ANN. Consider that ANN1 was taken for BA-related parameters, ANN2 for RHA-related parameters, and ANN3 for both BA- and RHS-related parameters. A total of 23 datasets for $\mathrm{BA}$ replacement, 25 datasets for RHA replacement, and 25 datasets for $\mathrm{BA}+\mathrm{RHA}$ replacement are used to train ANN1, ANN2, and ANN3. These datasets are validated by using the $R$ value.

It is evident from Figures $3-5$ that the $R$ value is in the acceptable range. Figure 3(a) indicates that $R$ value is about 0.7321 for standard consistency of cement. Similarly, from Figures 3(b) and 3(c), the $R$ values of 0.9991 and 0.999 prove that those prediction values of IST and FST are much closer to the actual experimental values. The $R$ value from 
TABle 1: Training datasets for ANN1-BA replacement.

\begin{tabular}{lccccc}
\hline $\begin{array}{l}\text { PPC } \\
(\%)\end{array}$ & $\begin{array}{c}\text { BA } \\
(\%)\end{array}$ & SC & $\begin{array}{c}\text { IST } \\
(\mathrm{min})\end{array}$ & $\begin{array}{c}\text { FST } \\
(\mathrm{min})\end{array}$ & $\begin{array}{c}\text { CS-28 days (N/ } \\
\left.\mathrm{mm}^{2}\right)\end{array}$ \\
\hline 96 & 4 & 0.37 & 107 & 267 & 27.52 \\
96 & 4 & 0.38 & 110 & 267 & 28.87 \\
96 & 4 & 0.39 & 95 & 257 & 27.34 \\
92 & 8 & 0.40 & 115 & 425.0 & 28.96 \\
92 & 8 & 0.40 & 108 & 417.0 & 28.03 \\
92 & 8 & 0.38 & 113 & 440.0 & 28.56 \\
92 & 8 & 0.37 & 114 & 425.0 & 29.15 \\
92 & 8 & 0.38 & 102 & 432.0 & 27.95 \\
88 & 12 & 0.39 & 281 & 758 & 25.18 \\
88 & 12 & 0.37 & 279 & 763 & 26.22 \\
88 & 12 & 0.38 & 271 & 762 & 26.10 \\
88 & 12 & 0.40 & 275 & 754 & 25.23 \\
88 & 12 & 0.38 & 270 & 761 & 25.27 \\
84 & 16 & 0.40 & 351 & 1018 & 23.67 \\
84 & 16 & 0.39 & 352 & 1008 & 23.63 \\
84 & 16 & 0.38 & 342 & 995 & 22.56 \\
84 & 16 & 0.41 & 341 & 1020 & 22.65 \\
84 & 16 & 0.42 & 340 & 1007 & 22.88 \\
80 & 20 & 0.44 & 403 & 1215 & 21.05 \\
80 & 20 & 0.45 & 405 & 1218 & 20.43 \\
80 & 20 & 0.42 & 405 & 1207 & 20.12 \\
80 & 20 & 0.38 & 401 & 1214 & 19.73 \\
80 & 20 & 0.44 & 398 & 1208 & 21.46 \\
\hline & & & & &
\end{tabular}

TABLE 2: Training dataset for ANN2-RHA replacement.

\begin{tabular}{lccccc}
\hline PPC (\%) & RHA (\%) & SC & IST (min) & FST (min) & $\begin{array}{c}\text { CS-28 days } \\
\left(\mathrm{N} / \mathrm{mm}^{2}\right)\end{array}$ \\
\hline 96 & 4 & 0.39 & 93 & 234 & 31.56 \\
96 & 4 & 0.38 & 95 & 239 & 31.02 \\
96 & 4 & 0.42 & 86 & 247 & 30.67 \\
96 & 4 & 0.4 & 88 & 244 & 31.97 \\
96 & 4 & 0.39 & 87 & 235 & 30.80 \\
92 & 8 & 0.42 & 113 & 410 & 30.35 \\
92 & 8 & 0.39 & 110 & 415 & 30.21 \\
92 & 8 & 0.39 & 102 & 412 & 29.67 \\
92 & 8 & 0.42 & 105 & 419 & 31.00 \\
92 & 8 & 0.42 & 103 & 406 & 29.36 \\
88 & 12 & 0.4 & 253 & 739 & 25.87 \\
88 & 12 & 0.37 & 257 & 729 & 26.94 \\
88 & 12 & 0.41 & 254 & 730 & 26.21 \\
88 & 12 & 0.41 & 248 & 731 & 25.64 \\
88 & 12 & 0.39 & 243 & 729 & 26.83 \\
84 & 16 & 0.39 & 328 & 934 & 21.30 \\
84 & 16 & 0.42 & 335 & 933 & 22.30 \\
84 & 16 & 0.41 & 339 & 924 & 21.60 \\
84 & 16 & 0.39 & 324 & 941 & 20.60 \\
84 & 16 & 0.42 & 320 & 928 & 21.80 \\
80 & 20 & 0.43 & 395 & 993 & 21.65 \\
80 & 20 & 0.45 & 396 & 987 & 21.13 \\
80 & 20 & 0.44 & 385 & 989 & 20.34 \\
80 & 20 & 0.46 & 386 & 994 & 20.81 \\
80 & 20 & 0.41 & 393 & 997 & 21.23 \\
\hline & & & & &
\end{tabular}

Figure 3(d) shows that experimental compressive strength values are equal to the predicted values of ANN1 with a correlation value of 0.9767 . The prediction of compressive strength for intermediate mix propositions of BA
TABLE 3: Training dataset for ANN3 (BA + RHA) replacement.

\begin{tabular}{lcccccc}
\hline $\begin{array}{l}\text { PPC } \\
(\%)\end{array}$ & $\begin{array}{c}\text { BA } \\
(\%)\end{array}$ & $\begin{array}{c}\text { RHA } \\
(\%)\end{array}$ & SC & $\begin{array}{c}\text { IST } \\
(\mathrm{min})\end{array}$ & $\begin{array}{c}\text { FST } \\
(\mathrm{min})\end{array}$ & $\begin{array}{c}\text { CS-28 days } \\
\left(\mathrm{N} / \mathrm{mm}^{2}\right)\end{array}$ \\
\hline 96 & 2 & 2 & 0.38 & 88 & 251 & 29.87 \\
96 & 2 & 2 & 0.4 & 95 & 258 & 28.37 \\
96 & 2 & 2 & 0.41 & 97 & 240 & 28.89 \\
96 & 2 & 2 & 0.41 & 89 & 238 & 30.21 \\
96 & 2 & 2 & 0.38 & 98 & 240 & 29.84 \\
92 & 4 & 4 & 0.4 & 106 & 421 & 28.97 \\
92 & 4 & 4 & 0.38 & 98 & 417 & 28.29 \\
92 & 4 & 4 & 0.39 & 96 & 406 & 27.64 \\
92 & 4 & 4 & 0.38 & 105 & 410 & 29.70 \\
92 & 4 & 4 & 0.39 & 104 & 420 & 27.97 \\
88 & 6 & 6 & 0.38 & 257 & 741 & 26.34 \\
88 & 6 & 6 & 0.37 & 259 & 732 & 24.32 \\
88 & 6 & 6 & 0.37 & 257 & 740 & 25.75 \\
88 & 6 & 6 & 0.41 & 260 & 729 & 24.86 \\
88 & 6 & 6 & 0.38 & 242 & 731 & 24.98 \\
84 & 8 & 8 & 0.42 & 338 & 985 & 22.59 \\
84 & 8 & 8 & 0.39 & 339 & 975 & 21.79 \\
84 & 8 & 8 & 0.38 & 340 & 954 & 22.38 \\
84 & 8 & 8 & 0.43 & 320 & 953 & 21.52 \\
84 & 8 & 8 & 0.39 & 338 & 958 & 20.24 \\
80 & 10 & 10 & 0.42 & 385 & 1125 & 21.02 \\
80 & 10 & 10 & 0.44 & 389 & 1117 & 20.07 \\
80 & 10 & 10 & 0.43 & 396 & 1142 & 19.95 \\
80 & 10 & 10 & 0.41 & 394 & 1135 & 19.04 \\
80 & 10 & 10 & 0.43 & 388 & 1131 & 21.00 \\
\hline & & & & & &
\end{tabular}

TABLE 4: Input parameter values for ANN networks.

\begin{tabular}{|c|c|c|c|c|}
\hline Other input parameters & PPC & BA & RHA & IS code \\
\hline Bulk density $\left(\mathrm{kg} / \mathrm{m}^{3}\right)$ & 1480 & 565 & 280 & $\begin{array}{c}\text { IS: } 4031-1988 \\
\text { (Part XI). }\end{array}$ \\
\hline Specific gravity & 3.11 & 1.82 & 2.08 & IS: $1727-1967$ \\
\hline Percentage passing $45 \mu \mathrm{m}$ & 30 & 100 & 100 & - \\
\hline Specific surface area $\left(\mathrm{m}^{2} / \mathrm{kg}\right)$ & 335 & 440 & 550 & $\begin{array}{l}\text { IS: } 4031-1988 \\
\quad \text { (Part II). } \\
\text { IS: } 3812-1981\end{array}$ \\
\hline
\end{tabular}

TABLE 5: Selection of best architecture for ANN.

\begin{tabular}{lcc}
\hline Number of hidden layers & $R$ & RMSE \\
\hline 2 & 0.9816 & 1.2393 \\
3 & 0.9817 & 0.9683 \\
4 & 0.9822 & 0.9875 \\
5 & 0.9823 & 0.9214 \\
6 & 0.9822 & 0.9926 \\
7 & 0.9819 & 0.9813 \\
8 & 0.9821 & 0.9852 \\
9 & 0.9816 & 1.0118 \\
10 & 0.982 & 0.9973 \\
\hline
\end{tabular}

replacement for which actual experiment was not carried out is also recorded using well-trained ANN1 as given in Table 6.

For predicting standard consistency, PPC, BA, BD, SG, and specific surface areas are considered as input for ANN1. For predicting IST and FST, the previously predicted SC is 


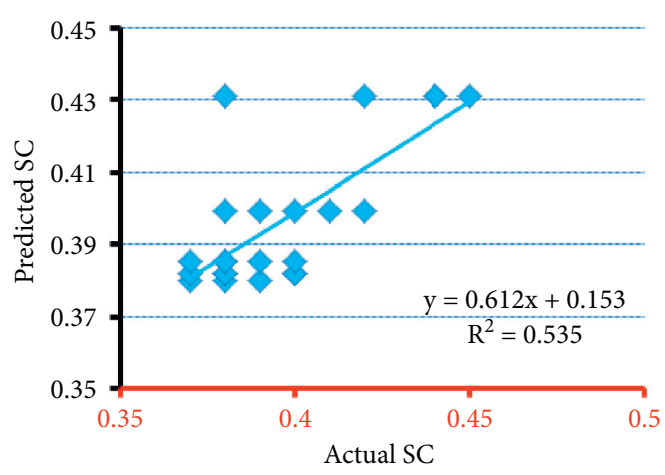

Correlation Coefficient : 0.7321

(a)

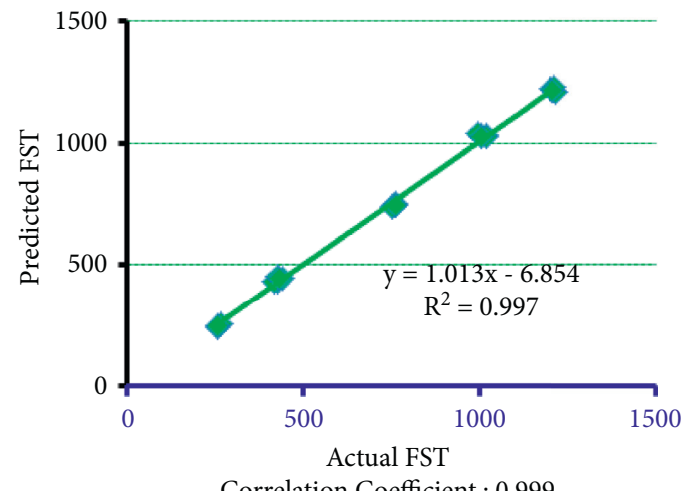

Correlation Coefficient : 0.999

(c)

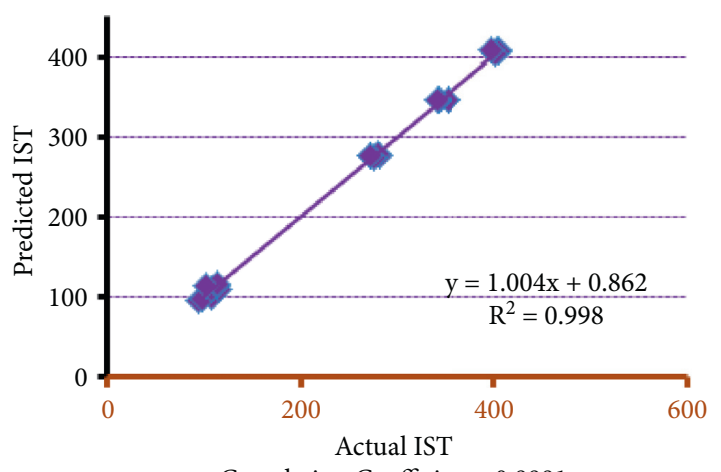

Correlation Coefficient : 0.9991

(b)

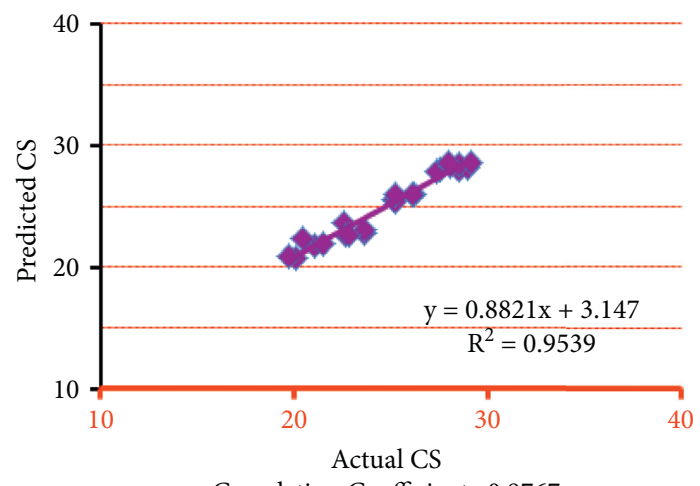

Correlation Coefficient : 0.9767

(d)

FIgURe 3: Physical properties of PPC for BA as a replacement. (a) Standard consistency; (b) initial setting time; (c) final setting time; (d) compressive strength of concrete.

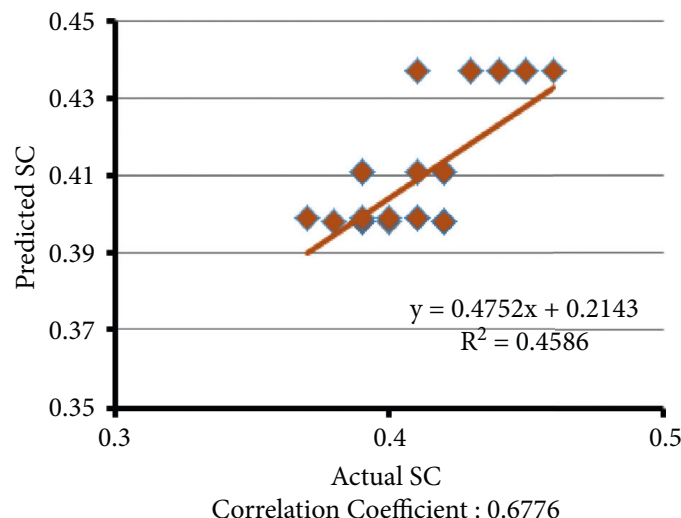

(a)

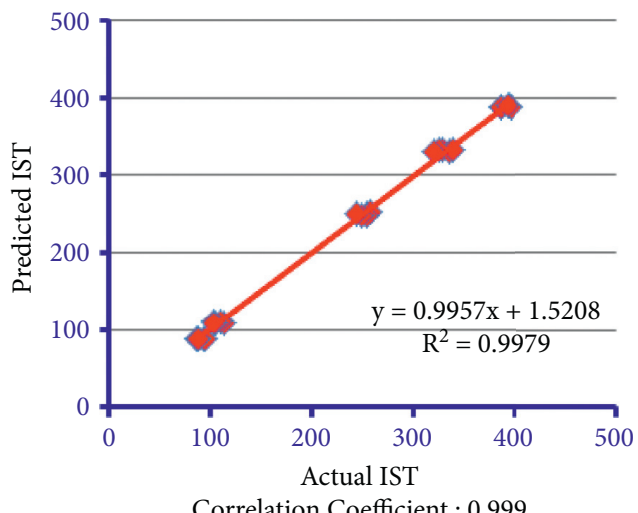

Correlation Coefficient : 0.999

(b)

Figure 4: Continued. 


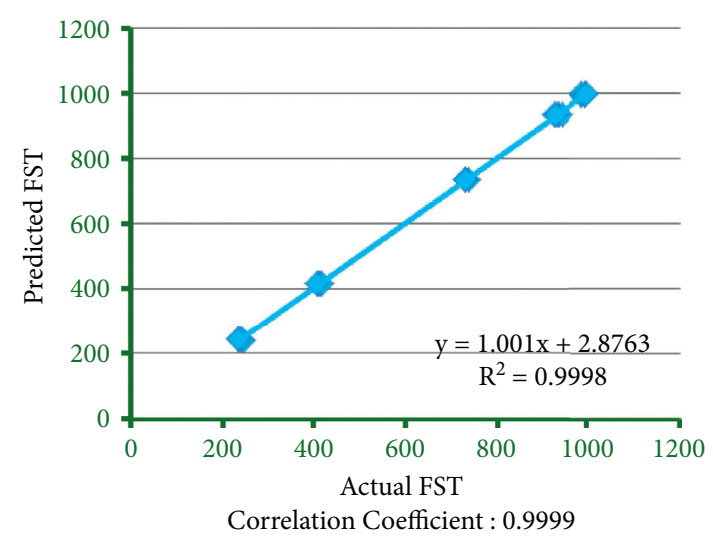

(c)

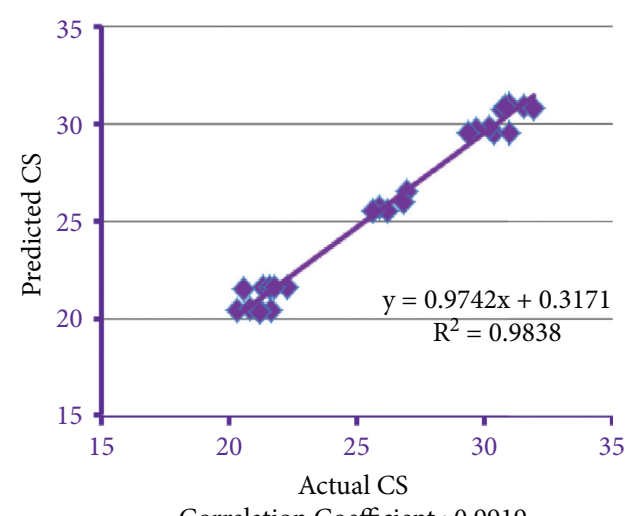

(d)

FIgURE 4: Physical properties of PPC for RHA as a replacement. (a) Standard consistency; (b) initial setting time; (c) final setting time; (d) compressive strength of concrete.

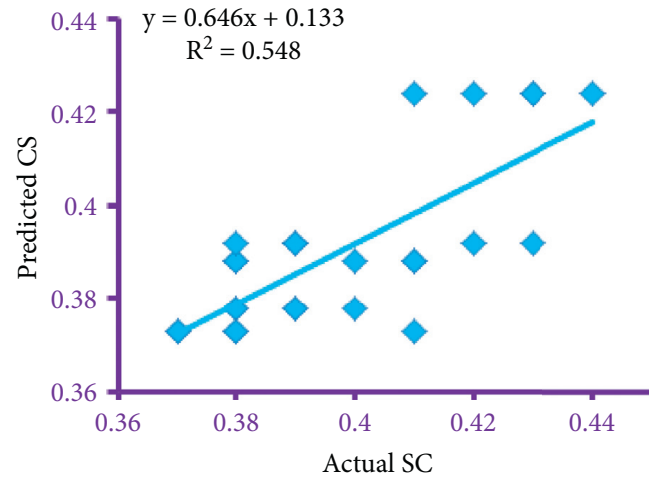

Correlation Coefficient : 0.741

(a)

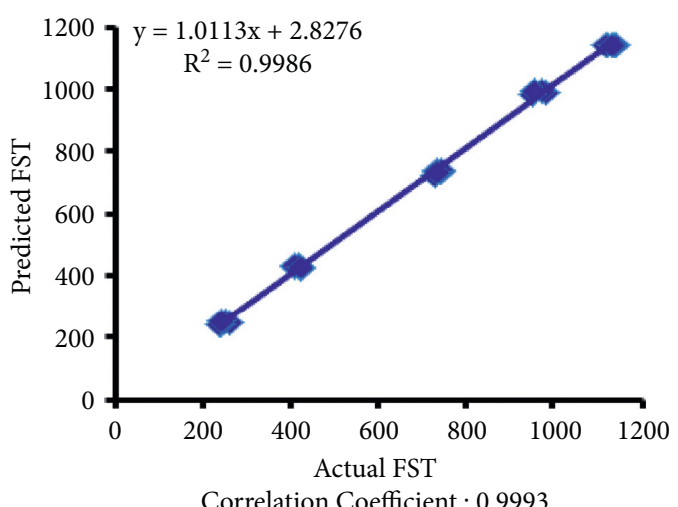

(c)

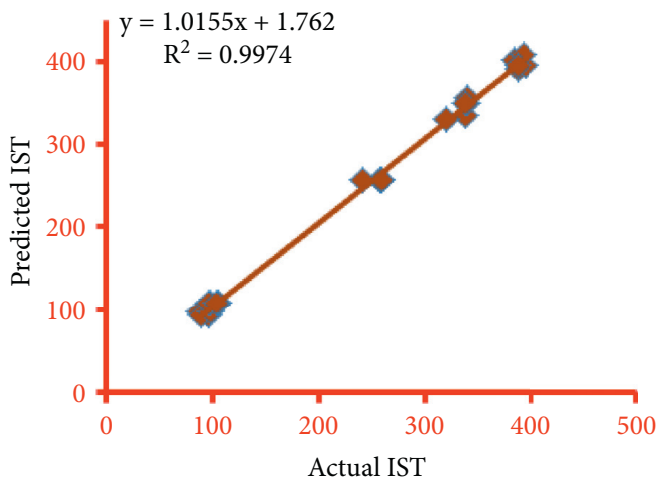

Correlation Coefficient : 0.9987

(b)

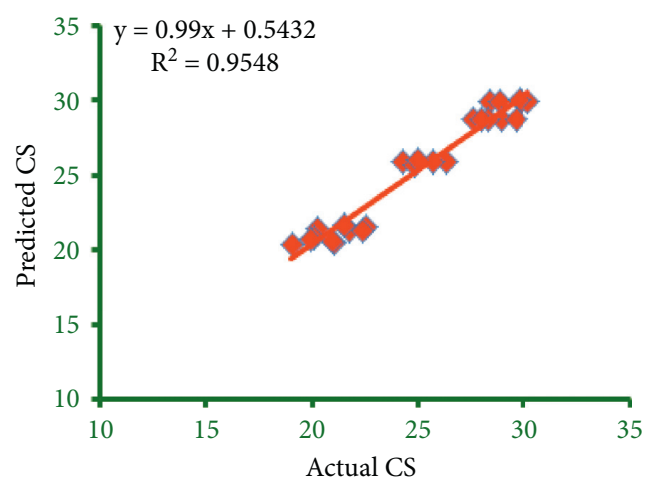

Correlation Coefficient : 0.977

(d)

FIgURE 5: Physical properties of PPC for RHA as a replacement. (a) Standard consistency; (b) initial setting time; (c) final setting time; (d) compressive strength of concrete.

considered as one of the inputs for ANN1. For predicting the compressive strength for 28 days, the predicted values of SC, IST, and FST are considered as inputs for ANN1. From Table 6, it is evident that, up to $13 \%$ replacement of BA, the compressive strength value is above $25 \mathrm{~N} / \mathrm{mm}^{2}$, which is the minimum compressive strength prescribed by IS 10262:2009 for M25 grade concrete.

Table 2 shows the training datasets of ANN2, where RHA is used as a replacement for cement. Input parameters are the same as those used for the BA replacement method. 
TABLE 6: Intermediate mix proposition of BA with PPC-test dataset for ANN1.

\begin{tabular}{lcccccc}
\hline S. no. & PPC $(\%)$ & BA $(\%)$ & Predicted SC & Predicted IST $(\mathrm{min})$ & Predicted FST $(\mathrm{min})$ & ${\text { Predicted CS-28 days }\left(\mathrm{N} / \mathrm{mm}^{2}\right)}^{2}$ \\
\hline 1 & 99 & 1 & 0.377 & 99.124 & 168.67 & 27.437 \\
2 & 98 & 2 & 0.378 & 98.59 & 189.186 & 27.621 \\
3 & 97 & 3 & 0.379 & 98.155 & 214.507 & 27.805 \\
4 & 95 & 5 & 0.381 & 98.227 & 283.119 & 28.156 \\
5 & 94 & 6 & 0.381 & 99.915 & 328.633 & 28.312 \\
6 & 93 & 7 & 0.382 & 104.197 & 381.482 & 28.405 \\
7 & 92 & 8 & 0.382 & 115.127 & 442.878 & 28.389 \\
8 & 89 & 11 & 0.384 & 232.702 & 664.366 & 25.005 \\
9 & 87 & 13 & 0.386 & 304.65 & 823.787 & 24.338 \\
10 & 86 & 14 & 0.389 & 321.386 & 898.931 & 23.637 \\
11 & 85 & 15 & 0.393 & 333.927 & 968.841 & 22.012 \\
12 & 83 & 17 & 0.408 & 360.002 & 1087.723 & 21.461 \\
13 & 82 & 18 & 0.418 & 375.556 & 1136.406 & 21.242 \\
14 & 81 & 19 & 0.426 & 391.863 & 1179.047 & 21.141 \\
15 & 80 & 20 & 0.431 & 407.715 & 1216.21 & \\
\hline
\end{tabular}

TABLE 7: Intermediate mix proposition of RHA with PPC-test dataset of ANN2.

\begin{tabular}{lcccccc}
\hline S. no. & PPC $(\%)$ & RHA $(\%)$ & Predicted SC & Predicted IST (min) & Predicted FST (min) & Predicted CS-28 days (N/mm $\left.{ }^{2}\right)$ \\
\hline 1 & 99 & 1 & 0.398 & 87.325 & 199.2 & 31.344 \\
2 & 98 & 2 & 0.398 & 87.493 & 209.19 & 31.195 \\
3 & 97 & 3 & 0.398 & 87.856 & 223.094 & 31.032 \\
4 & 95 & 5 & 0.398 & 90.009 & 269.427 & 30.644 \\
5 & 94 & 6 & 0.398 & 92.861 & 306.139 & 30.402 \\
6 & 93 & 7 & 0.398 & 98.624 & 354.724 & 30.11 \\
7 & 92 & 8 & 0.398 & 110.131 & 416.252 & 29.738 \\
8 & 89 & 11 & 0.398 & 209.562 & 655.175 & 27.277 \\
9 & 87 & 13 & 0.4 & 280.187 & 803.255 & 24.281 \\
10 & 86 & 14 & 0.402 & 301.353 & 859.577 & 23.078 \\
11 & 85 & 15 & 0.406 & 317.674 & 903.067 & 22.192 \\
12 & 83 & 17 & 0.418 & 346.656 & 958.797 & 21.142 \\
13 & 82 & 18 & 0.426 & 361.054 & 975.525 & 20.839 \\
14 & 81 & 19 & 0.432 & 375.411 & 987.68 & 20.602 \\
15 & 80 & 20 & 0.437 & 389.161 & 996.587 & 20.404 \\
\hline
\end{tabular}

TABLE 8: Intermediate mix proposition of BA + RHA with PPC-test dataset of ANN3.

\begin{tabular}{lccccccc}
\hline S. no. & PPC $(\%)$ & BA $(\%)$ & RHA\% & Predicted SC & Predicted IST (min) & Predicted FST (min) & Predicted CS-28 days (N/mm $\left.{ }^{2}\right)$ \\
\hline 1 & 99 & 0.5 & 0.5 & 0.378 & 108.255 & 435.945 & 28.772 \\
2 & 98 & 1 & 1 & 0.38 & 99.56 & 376.038 & 29.047 \\
3 & 97 & 1.5 & 1.5 & 0.382 & 96.221 & 325.555 & 29.333 \\
4 & 95 & 2.5 & 2.5 & 0.385 & 95.38 & 283.389 & 29.63 \\
5 & 94 & 3 & 3 & 0.391 & 96.765 & 219.953 & 30.253 \\
6 & 93 & 3.5 & 3.5 & 0.395 & 97.967 & 195.672 & 30.568 \\
7 & 92 & 4 & 4 & 0.399 & 99.319 & 175.069 & 27.251 \\
8 & 89 & 5.5 & 5.5 & 0.374 & 208.69 & 660.171 & 24.222 \\
9 & 87 & 6.5 & 6.5 & 0.374 & 296.348 & 818.668 & 22.966 \\
10 & 86 & 7 & 7 & 0.376 & 319.725 & 881.491 & 21.971 \\
11 & 85 & 7.5 & 7.5 & 0.382 & 336.989 & 940.54 & 20.965 \\
12 & 83 & 8.5 & 8.5 & 0.405 & 359.496 & 1036.452 & 20.779 \\
13 & 82 & 9 & 9 & 0.415 & 371.002 & 1075.988 & 20.673 \\
14 & 81 & 9.5 & 9.5 & 0.421 & 384.772 & 1110.837 & 20.598 \\
15 & 80 & 10 & 10 & 0.424 & 399.641 & 1141.431 & \\
\hline
\end{tabular}


Instead of BA, RHA is used in validating and predicting the compressive strength of the concrete. From Figure 4(a), it is evident that the validated value of the Standard Consistency of cement is within the acceptable value of $R$ of 0.6776 of ANN2. The $R$ values for IST and FST of RHA replacement were found to be 0.999 and 0.9999 , respectively (Figures 4(b) and $4(\mathrm{c}))$. This proves that the experimental values are validated with the predicted values generated by ANN2. From Figure 4(d), the $R$ value of compressive strength for 28 days is obtained to be 0.9919 . Thus, all the experimental results are validated using the high $R$ values resulting in the predicted values of ANN2. The test dataset for well-trained ANN2 and predicted values of Standard Consistency, IST, FST, and compressive strength of concrete for 28 days are as given in Table 7. The RHA as replacement up to $11 \%$ is following the IS 10262:2009 code; that is, the compressive strength for 28 days was more than $25 \mathrm{~N} / \mathrm{mm}^{2}$ through ANN2 [38].

The training datasets for ANN3 are given in Table 3. For ANN3, BA + RHA is used as a replacement in an equal proposition for cement. Similar to the BA replacement method, input parameters are the same. But, instead of BA, both BA and RHA are used in validating and predicting the compressive strength of the concrete. It is obvious from Figures 5(a) to 5(d) that the experimental datasets for SC, IST, FST, and compressive strength are validated using the values predicted by ANN3. The $R$ values of $0.741,0.9987$, 0.9993 , and 0.977 generated by the ANN3 network are in an acceptable range. The dataset in Table 8 is used as test data, which is the intermediate mix proposition for a well-trained ANN3 network that is used to predict the compressive strength. From Table 8 , it is evident that $11 \%$ replacement of PPC with equal proposition of $\mathrm{BA}+\mathrm{RHA}$ resulted in compressive strength more than $25 \mathrm{~N} / \mathrm{mm}^{2}$, according to IS 10262:2009 code.

\section{Conclusion}

An experimentation to use $\mathrm{ANN}$ to estimate the core compressive strength of an SCC is presented in this paper. Three datasets are used to train and test the proposed ANN model with various $\mathrm{BA}, \mathrm{RHA}$, and $\mathrm{BA}+\mathrm{RHA}$ mix propositions. Using ANNs in SCC mixes prediction is reaffirming as the model resulted in a good $R 2$ value. Using the correlation coefficient $(R)$ and root mean square error (RMSE) as stopping criteria for the epochs value of 500, learning rate of 0.3 , and momentum of 0.2 , the simulation results were recorded by altering the number of hidden layers from 2 to 10 to determine the optimum architecture. The $R$ and RMSE values are determined. For 5 hidden layers, the highest $R$ value achieved was as 0.9823 , and the minimum RMSE value was found to be 0.9214 . ANN1 was used for BA-related parameters, ANN2 for RHA-related parameters, and ANN3 for both BA- and RHS-related parameters to verify and forecast compressive strength for 28 days. To train ANN1, ANN2, and ANN3, a total of 23 datasets for BA replacement, 25 datasets for RHA replacement, and 25 datasets for $\mathrm{BA}+\mathrm{RHA}$ replacement were employed. The $R$ value was used to verify these datasets. The RMSE values of ANN1,
ANN2, and ANN3 models with the three distinct datasets were $0.97,0.99$, and 0.97 , respectively, when the number of hidden layers was 5. Thus, an ANN model proposed in this paper was used to predict the core compressive strength of SCC with the high correlation coefficient and validated datasets. It is found from the study's results that the ANN could be utilized to make predictions about the core compressive strength of concrete which eliminates the investigation work that is time-consuming, laborious, and expensive and requires skilled manpower such as structural engineers and practitioners.

\section{Data Availability}

The data used to support the findings of this study are included within the article.

\section{Conflicts of Interest}

The authors declare that there are no conflicts of interest.

\section{References}

[1] M. Nehdi, H. El Chabib, and H. El Naggar, "Predicting performance of self-compacting concrete mixtures using artificial neural network," ACI Materials Journal, vol. 98, no. b5, pp. 394-401, 2001.

[2] Y. Aggarwal and P. Aggarwal, "Prediction of compressive strength of SCC containing bottom ash using artificial neural networks," Engineering and Technology, vol. 21, pp. 1-6, 2011.

[3] A. J. Prakash, D. Sathyan, K. B. Anand, and N. R. Aravind, "Comparison of ANN and RKS approaches to model SCC strength," IOP Conference Series: Materials Science and Engineering, vol. 310, no. 1, Article ID 012037, 2018.

[4] H. A. Oliveira Junior, A. M. Caldeira, M. A. S. Machado, R. C. Souza, and R. Tanscheit, Computational Intelligence Applied to the Administrative, Economics and Engineering in Matlab, Thomson Learning, New York, NY, USA, 2007.

[5] J. Mansoor, S. Shah, M. Khan et al., "Analysis of mechanical properties of self compacted concrete by partial replacement of cement with industrial wastes under elevated temperature," Applied Sciences, vol. 8, no. 3, p. 364, 2018.

[6] M. Abu Yaman, M. Abd Elaty, and M. Taman, "Predicting the ingredients of self compacting concrete using artificial neural network," Alexandria Engineering Journal, vol. 56, no. 4, pp. 523-532, 2017.

[7] M. Al Khatib and S. Al Martini, "A study on the application of artificial neural networks on green self consolidating concrete (SCC) under hot weather," Key Engineering Materials, vol. 677, pp. 254-259, 2016.

[8] M. Uysal and H. Tanyildizi, "Predicting the core compressive strength of self-compacting concrete (SCC) mixtures with mineral additives using artificial neural network," Construction and Building Materials, vol. 25, no. 11, pp. 4105-4111, 2011.

[9] A. P. Braga, A. P. L. F. Carvalho, and T. B. Ludermir, Artificial Neural Networks: Theory and Applications, LTC”. Portuguese, Rio de Janeiro, Brazil, 2nd edition, 2000.

[10] W. P. S. Dias and S. P. Pooliyadda, "Neural networks for predicting properties of concretes with admixtures," Construction and Building Materials, vol. 15, no. 7, pp. 371-379, 2001. 
[11] T. R. Krishnasamy and M. Palanisamy, "Bagasse ash and rice husk ash as cement replacement in self-compacting concrete," Građevinar, vol. 67, no. 1, pp. 23-31, 2015.

[12] B. K. R. Prasad, H. Eskandari, and B. V. V. Reddy, "Prediction of compressive strength of SCC and HPC with high volume fly ash using ANN," Construction and Building Materials, vol. 23, no. 1, pp. 117-128, 2009.

[13] T. Ji, T. Lin, and X. Lin, "A concrete mix proportion design algorithm based on artificial neural networks," Cement and Concrete Research, vol. 36, no. 7, pp. 1399-1408, 2006.

[14] H. El-Chabib, M. Nehdi, and M. Sonebi, "Artificial intelligence model for flowable concrete mixtures used in underwater construction and repair," Materials Journal, vol. 100, no. 2, pp. 165-173, 2003.

[15] H.-G. Ni and J.-Z. Wang, "Prediction of compressive strength of concrete by neural networks," Cement and Concrete Research, vol. 30, no. 8, pp. 1245-1250, 2000.

[16] G. Deshpande, P. Wang, D. Rangaprakash, and B. Wilamowski, "Fully connected cascade artificial neural network architecture for attention deficit hyperactivity disorder classification from functional magnetic resonance imaging data," IEEE Transactions on Cybernetics, vol. 45, no. 12, pp. 2668-2679, 2015.

[17] A. Oztas, M. Pala, E. Ozbay, E. Kanca, N. Caglar, and M. A. Bhatti, "Predicting the compressive strength and slump of high strength concrete using neural network," Construction and Building Materials, vol. 20, no. 9, pp. 769-775, 2006.

[18] C. Bilim, C. D. Atiş, H. Tanyildizi, and O. Karahan, "Predicting the compressive strength of ground granulated blast furnace slag concrete using artificial neural network," Advances in Engineering Software, vol. 40, no. 5, pp. 334-340, 2009.

[19] R. Siddique, P. Aggarwal, and Y. Aggarwal, "Prediction of compressive strength of self-compacting concrete containing bottom ash using artificial neural networks," Advances in Engineering Software, vol. 42, no. 10, pp. 780-786, 2011.

[20] S. J. Hakim, J. Noorzaei, M. S. Jaafar, M. Jameel, and M. Mohammadhassani, "Application of artificial neural networks to predict compressive strength of high strength concrete," International Journal of the Physical Sciences, vol. 6, no. 5, pp. 975-981, 2011.

[21] I.-C. Yeh, "Modeling of strength of high-performance concrete using artificial neural networks," Cement and Concrete Research, vol. 28, no. 12, pp. 1797-1808, 1998.

[22] M. Nehdi, H. E. Chabib, and M. H. E. Naggar, "Predicting performance of self-compacting concrete mixtures using artificial neural," ACI Materials Journal, vol. 98, no. 5, pp. 349-401, 2001.

[23] X. Wu, J. Ghaboussi, and J. H. Garrett Jr., "Use of neural networks in detection of structural damage," Computers \& Structures, vol. 42, no. 4, pp. 649-659, 1992.

[24] H. Adeli and H. S. Park, "A neural dynamics model for structural optimization-Theory," Computers \& Structures, vol. 57, no. 3, pp. 383-390, 1995.

[25] J. Ghaboussi, J. H. Garrett Jr., and X. Wu, "Knowledge-based modeling of material behavior with neural networks," Journal of Engineering Mechanics, vol. 117, no. 1, pp. 132-153, 1991.

[26] Ô. Erkan, B. Işık, A. Çiçek, and F. Kara, "Prediction of damage factor in end milling of Glass fibre reinforced plastic composites using artificial neural network," Applied Composite Materials, vol. 20, no. 4, pp. 517-536, 2013.

[27] Y. Çay, A. Çiçek, F. Kara, and S. Sağiroğlu, "Prediction of engine performance for an alternative fuel using artificial neural network," Applied Thermal Engineering, vol. 37, pp. 217-225, 2012.

[28] F. Kara, K. Aslantaş, and A. Çiçek, "Prediction of cutting temperature in orthogonal machining of AISI 316L using artificial neural network," Applied Soft Computing, vol. 38, pp. 64-74, 2016.

[29] M. Ayyıldız and K. Çetinkaya, "Predictive modeling of geometric shapes of different objects using image processing and an artificial neural network," Proceedings of the Institution of Mechanical Engineers-Part E: Journal of Process Mechanical Engineering, vol. 231, no. 6, pp. 1206-1216, 2017.

[30] J. F. López-Perales, J. M Contreras, F. J. Vázquez-Rodríguez et al., "Partial replacement of a traditional raw material by blast furnace slag in developing a sustainable conventional refractory castable of improved physical-mechanical properties," Journal of Cleaner Production, vol. 306, Article ID 127266, 2021.

[31] D. Tavakoli, P. Fakharian, and J. de Brito, "Mechanical properties of roller-compacted concrete pavement containing recycled brick aggregates and silica fume," Road Materials and Pavement Design, vol. 23, pp. 1-22, 2021.

[32] M. Ramadan, M. S. Amin, S. A. Waly, and A. Mohsen, "Effect of high gamma radiation dosage and elevated temperature on the mechanical performance of sustainable alkali-activated composite as a cleaner product," Cement and Concrete Composites, vol. 121, Article ID 104087, 2021.

[33] F. Ameri, P. Shoaei, M. Zahedi, M. Karimzadeh, H. R. Musaeei, and C. B. Cheah, "Physico-mechanical properties and micromorphology of AAS mortars containing copper slag as fine aggregate at elevated temperature," Journal of Building Engineering, vol. 39, Article ID 102289, 2021.

[34] M. Thiruvenkitam, S. Pandian, M. Santra, and D. Subramanian, "Use of waste foundry sand as a partial replacement to produce green concrete: mechanical properties, durability attributes and its economical assessment," Environmental Technology \& Innovation, vol. 19, Article ID 101022, 2020.

[35] G. F. Huseien, A. R. M. Sam, K. W. Shah, and J. Mirza, "Effects of ceramic tile powder waste on properties of self-compacted alkali-activated concrete," Construction and Building Materials, vol. 236, Article ID 117574, 2020.

[36] N. Hilal, R. D. Saleh, N. B. Yakoob, and Q. S. Banyhussan, "Utilization of ceramic waste powder in cement mortar exposed to elevated temperature," Innovative Infrastructure Solutions, vol. 6, no. 1, pp. 1-12, 2020.

[37] D. Tavakoli, P. Fakharian, and J. de Brito, "Mechanical properties of roller-compacted concrete pavement containing recycled brick aggregates and silica fume," Road Materials and Pavement Design, vol. 87, pp. 1-22, 2021.

[38] M. Samadi, G. F. Huseien, H. Mohammadhosseini et al., "Waste ceramic as low cost and eco-friendly materials in the production of sustainable mortars," Journal of Cleaner Production, vol. 266, Article ID 121825, 2020. 